\title{
Reduction of the nosocomial meticillin-resistant Staphylococcus aureus incidence density by a region- wide search and follow-strategy in forty German hospitals of the EUREGIO, 2009 to 2011
}

A Jurke¹, R Köck², K Becker³, S Thole¹, R Hendrix4, J Rossen4, I Daniels-Haardt5, A W Friedrich (alex.friedrich@umcg.nl)4

1. Department of Infectiology and Hygiene, NRW Centre for Health, Münster, Germany

2. Institute of Hygiene, University Hospital Münster, Germany

3. Medical Microbiology, University Hospital Münster, Germany

4. Department of Medical Microbiology, University of Groningen, University Medical Center Groningen, the Netherlands

5. Department of Health Protection, Health Monitoring, NRW Centre for Health, Münster, Germany

Citation style for this article:

Jurke A, Köck R, Becker K, Thole S, Hendrix R, Rossen J, Daniels-Haardt I, Friedrich AW. Reduction of the nosocomial meticillin-resistant Staphylococcus aureus incidence density by a region-wide search and follow-strategy in forty German hospitals of the EUREGIO, 2009 to 2011.

Euro Surveill. 2013;18(36):pii=20579. Available online: http://www.eurosurveillance.org/ViewArticle.aspx?Articleld=20579

Meticillin-resistant Staphylococcus aureus (MRSA) disseminates between hospitals serving one patient catchment area. Successful prevention and control requires concerted efforts and regional surveillance. Forty hospitals located in the German EUREGIO have established a network for combating MRSA. In 2007 they agreed upon a synchronised strategy for screening of risk patients and a standard for transmissionbased precautions (search and follow). The same year, the hospitals started synchronised MRSA prevention and annually reporting MRSA-data to the public health authorities. The median rate of screening cultures per 100 patients admitted increased from 4.38 in 2007 to 34.4 in 2011 (p<0.0001). Between 2007 and 2011, the overall incidence density of MRSA ( 0.87 MRSA cases/1,000 patient days vs $1.54 ;$ p $<0.0001$ ) increased significantly. In contrast, both the incidence density of nosocomial MRSA cases ( 0.13 nosocomial MRSA cases/1,000 patient days in 2009 vs 0.08 in 2011; $\mathrm{p}=0.0084$ ) and the MRSA-days-associated nosocomial MRSA rate (5.51 nosocomial MRSA cases/1,000 MRSA days in 2009 vs 3.80 in $2011 ; p=0.0437$ ) decreased significantly after the second year of the project. We documented adherence to the regional screening strategy resulting in improved detection of MRSA carriers at admission. Subsequently, after two years the nosocomial MRSA-incidence density was reduced. Regional surveillance data, annually provided as benchmarking to the regional hospitals and public health authorities, indicated successful prevention.

\section{Introduction}

Meticillin-resistant Staphylococcus aureus (MRSA) globally belongs to the most frequent causes of healthcareassociated infections [1]. In addition, the severity of MRSA infections is documented by studies estimating that patients with MRSA bloodstream infection (BSI) have a higher 30-day mortality compared to those with BSI due to meticillin-susceptible S. aureus (MSSA) [2].

In 2007, the annual burden of MRSA infections in European Union (EU) Member States, Iceland and Norway was estimated to comprise 171,200 cases including $12 \% \mathrm{BSI}$ [3]. However, MRSA rates in Europe show remarkable differences: In 2010, Sweden reported the lowest proportion of invasive isolates resistant to meticillin ( $0.5 \%$ of all $S$. aureus) and Portugal the highest (52.2\%) [4]. Such discrepancies were even reported when comparing directly neighbouring countries. In the German federal state of North Rhine-Westphalia (NRW), 57.6 MRSA bacteraemia episodes per 1,000,000 inhabitants were reported to public health authorities in 2010, whereas only a few kilometres across the Dutch-German border the rate of bacteraemia episodes was estimated to be 1.8 per $1,000,000$ inhabitants in the Netherlands $[5,6]$. Hence, the prevalence of MRSA differs nationally and regionally. Moreover, it was found that there are substantial regional differences regarding the molecular subtypes of MRSA circulating in Europe [7] and that compared with other continents, which observed a shift of the major MRSA burden from healthcare institutions into the community, healthcare-associated (HA-) MRSA are still predominant in Europe [8].

The molecular epidemiology of MRSA in Europe indicates that the dissemination of MRSA is mainly governed either by direct transfer of patients between hospitals, nursing homes and other healthcare facilities or by indirect exchange of patients admitted consecutively to several facilities in one same catchment area [7]. Indeed, of 354 MRSA carriers identified at admission to German hospitals, 32 were directly transferred from other hospitals, 173 had been hospitalised for $>24 \mathrm{~h}$ in the previous six months and 58 were 
residents of long-term care facilities [9]. Other studies have shown that patients once identified as MRSA carriers had a $44 \%$ probability of being re-admitted to the same or other regional hospitals whilst still carrying MRSA [10] and that of 1,032 known patients with previous MRSA carriage attending the Hannover Medical School hospital, $39 \%$ were re-admitted more than once during a 46-month period, $59 \%$ of which remained MRSA positive during all admissions [11]. Simulating the importance of inter-facility patient movements, it has been shown that especially small long-term care facilities with low patient turnover rates are most susceptible to sustaining high MRSA prevalence, especially when cooperating with large, high-prevalence hospitals [12]. A model based on patient-flow characteristics of 29 acute care hospitals cooperating in Orange County, California, revealed that in case of an outbreak (increase of MRSA prevalence to $15 \%$ ) in a single hospital within the county, most other regional hospitals also experienced an increase of the MRSA prevalence (median increase of MRSA prevalence $1.8 \%)$. In this model, even outbreaks in single intensive care units affected the overall prevalence of MRSA in regional acute care hospitals [13].

In consequence, the referral of patients between regional hospitals might contribute to MRSA spread. Thus preventive standards for MRSA control implemented only locally in single hospitals may be not effective to reduce MRSA. The implementation of harmonised preventive standards in the regional healthcare cluster, where the nosocomial pathogen spreads predominantly is more likely to be successful. The hospitals of the Dutch-German border region EUREGIO have been confirmed to represent such a regional healthcare cluster using mathematical modelling [14]. Therefore, the governments of the 16 German Bundesländer (i.e. federal states) have recommended to address the problem of antimicrobial resistance in regional networks of hospitals and other institutions involved in patient care [15], and to apply regional approaches and concerted regional action to solve the MRSA problem $[15,16]$. In addition, the implementation of preventive interventions including screening of defined risk patients, single or cohort room isolation and the use of transmission-based precautions (gloves, gowns) when caring for MRSA colonised or infected patients $[17,18]$ has been recommended for all German acute care hospitals. However, despite the availability of guidance [19], it was shown that for German hospitals it is challenging to implement preventive bundles sufficiently and in a standardised manner on a local and regional level [20]. To reinforce regional cooperation and overcome the problem of limited local implementation, all 40 hospitals in the Münsterland region in NRW are cooperating in the EU-funded Dutch-German EUREGIO MRSA-net (www.mrsa-net.eu) and EurSafety HealthNet (www.eursafety.eu) projects since 2005. Since these 40 hospitals form a connected healthcare cluster [14], and contain all hospitals in the region, they can be considered to form a single patient catchment area.
In 2007, hospitals agreed upon and started the implementation of a concerted strategy for identification of MRSA carriers by (pre)admission MRSA screening of risk patients, isolation of carriers, continued care and decolonisation even after transfer to another hospital or after discharge and collection of basic MRSA surveillance data for centralised analysis and benchmarking $[9,15]$. In this report, we analyse surveillance data collected between 2007 and 2011 resulting from the network with respect to changes in the implementation of MRSA screening and the number and incidences of imported and nosocomial MRSA cases.

\section{Methods}

The German part of the project region geographically comprises six German districts (codes DEA33, DEA34,

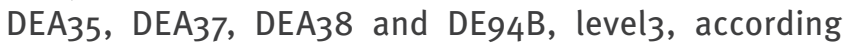
to the Nomenclature of Territorial Units for Statistics) [21] and is inhabited by 1.7 million people. In 2007, 40 hospitals were located in the region, treating about 360,000 patient cases during $2,500,000$ inpatient days per year. Of 40 hospitals, 36 were acute care hospitals, while one was a rehabilitation clinic and three hospitals were specialised in psychiatry.

During a prevalence screening of all admissions and risk factor assessment in November 2006, 35.6\% of patients admitted to the hospital had at least one MRSA risk factor [9]. In 2007, all hospitals started to systematically screen defined patients associated with any one of the known risk factors described previously [9], prior to or at admission to hospital. In 2008, the risk factors were slightly adapted according to a new German national recommendation [18]. In the project there was no harmonised microbiological protocol for performing the MRSA screening. Mostly a culturebased approach using chromogenic MRSA media was used. Positive screening was followed in all hospitals by the implementation of single or cohort room isolation, transmission-based precautions and decolonisation therapies as recommended in Germany [17]. Adherence to the recommendations was checked exemplarily by the local public health authorities during annual inspections.

Since 2007 standardised MRSA-related data were collected, based on a surveillance protocol adapted from that of the national German Nosocomial Infections Surveillance System to ensure comparability [22]. We analysed and reported all surveillance results and reported once a year to the participating hospitals in an anonymised feedback data set via the responsible public health offices.

\section{Data collection}

The collected surveillance data included the numbers of MRSA cases (colonisation and infection) classified as imported or nosocomial cases, the overall number of patient cases treated and the overall number of patient days as well as patient days of MRSA cases and the number of nasal swabs performed at admission. The 
findings of at least each MRSA-detection based on the first positive isolates of all MRSA-inpatient cases were inserted in a database (Epi-MRSA $\Re$, Ridom $\mathrm{GmbH}$, Münster, Germany or Excel ${ }^{\circ}$, Microsoft Inc., Redmond, USA). For each case, information on every first MRSA isolate was included in an annual report to the public health authorities with one exception: if a patient developed a MRSA bacteraemia during the hospital stay, this detection of MRSA-bacteraemia based on the positive MRSA blood culture isolate was included in the report. Each MRSA-detection (colonisation or infection) of isolates sampled more than three days after admission was classified as nosocomial unless the patient was a known MRSA carrier. A day, which an MRSA patient spent in hospital, was classified as MRSA-inhospital day. In most hospitals, the MRSA-in-hospital days could be specified by counting the isolation days of MRSA cases.

\section{Data analysis}

We analysed the surveillance data of five years (20072011) and calculated the following parameters: (i) number of MRSA cases, classified as imported or nosocomial cases, (ii) screening rate (number of screening cultures/100 admissions), (iii) MRSA incidence at admission (imported MRSA cases/100 admitted cases), (iv) MRSA incidence density (MRSA cases/1,000 patient days), (v) nosocomial MRSA incidence density (nosocomial MRSA-cases/1,000 patient days), (vi) the mean daily MRSA-burden (MRSA-in-hospital days/100 patient days), (vii) MRSA-days-associated nosocomial MRSA rate (nosocomial MRSA-cases/1,000 MRSA days).

Time trends of MRSA parameters were analysed by Friedmann test ( $p<0.05$ was considered significant). The percentage of nosocomial MRSA cases on all MRSA cases was assessed by Cochran Armitage test of linear trend ( $p<0.05)$. The correlation of MRSA parameters was done calculating the Spearman rank correlation coefficient ( $p<0.05)$. All statistical analyses were done using SAS 9.2 software (SAS Institute Inc., Cary, USA). Results of significance tests were discarded if the programme displayed an alert due to more than $10 \%$ of missing values in the respective dataset.

\section{Results}

In this study, we collected MRSA-related data of regional hospitals in the EUREGIO during a five-year period. While in 2007 and 2008, 38/40 hospitals (95\%) participated in surveillance, the participation rate was $100 \%$ in 2009 (40/40 hospitals), 2010 (38/38 hospitals) and 2011 (37/37 hospitals). The number of participating hospitals changed from 40 to 37 because of acute care hospital fusions.

Overall, the implementation of the screening strategy as monitored by analysis of the median screening rate increased significantly ( $p<0.001)$ over time from 4.38/100 patients (interquartile range (IQR): $2.15-11.8$ ) admitted in 2007 to $34.4 / 100$ patients (IQR: $27.4-51.6$ ) in 2011 (Table 1, Figure 1).

Table 2 shows the numbers of documented regional MRSA cases. In 2007, the total number of cases was 2,351. For 1,864 of these cases stratification into imported $(1,481)$ and nosocomial $(383)$ cases was possible (Table 2). Between 2007 and 2011, the overall number of cases increased significantly ( $p<0.0001$ ). According to Cochran Armitage trend test, the percentages of imported cases on all MRSA cases increased significantly ( $p<0.0001$ ) between 2007 and 2011, while the percentage of nosocomial cases on all MRSA cases decreased significantly (p<0.0001) (Table 2).

From 2007 to 2011, the MRSA admission incidence (0.51 vs 1.09 MRSA cases/100 patients admitted), the MRSAincidence density ( 0.87 vs 1.54 MRSA cases/1,000 patient days) as well as the mean daily MRSA-burden (1.30 vs 1.82 MRSA-in-hospital days/100 patient days) increased significantly ( $p<0.0001$ ) (Table 1). These overall increases were due to increases in the years from 2007 to 2009. From 2009 to 2011, the MRSA admission incidence $(p=0.5796)$, the MRSA incidence density $(p=0.6729)$ and the mean daily MRSA-burden $(p=0.7327)$ remained stable.

The incidence density of nosocomial cases decreased from 0.14 nosocomial MRSA cases per 1,000 patient days in 2007 to 0.08 per 1,000 patient days in 2011

\section{FIGURE 1}

Distribution of increasing screening rate at admission to identify meticillin-resistant Staphylococcus aureus (MRSA) carriers in German regional hospitals of the EUREGIO, 2007-2011 ( $\mathrm{n}=40)$

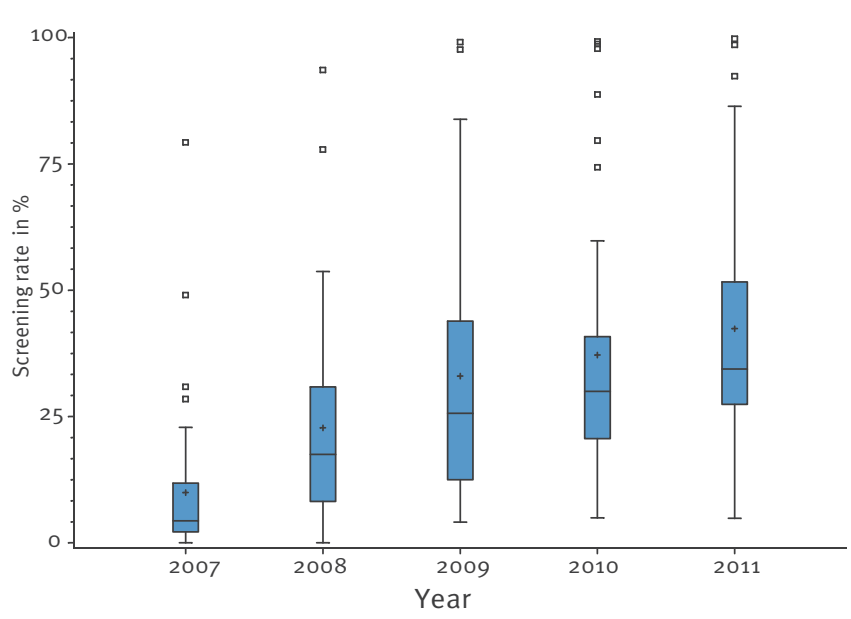

IQR: interquartile range.

Distribution of nasopharyngeal admission screening cultures per 100 patients admitted to the 40 German hospitals of the EUREGIO taking part in a concerted strategy for identification of MRSA carriers. For each year the number of screenings per 100 patients is shown in the boxplot with whiskers as minimum and maximum and outliers as squares below $1.5^{\star} \mid Q^{*} 25^{\text {th }}$ percentile or above $1.5^{\star} I Q R^{\star} 75^{\text {th }}$ percentile and far outliers above $3^{\star} I Q R^{\star} 75^{\text {th }}$ percentile. $50 \%$ of hospitals reported a screening rate indicated in the rectangle with the mean (plus) and the median (band). 
(Table 1). The MRSA-days-associated nosocomial MRSA rate decreased from 9.52 nosocomial MRSA cases per 1,000 MRSA days in 2007 to 8.14 in 2008 and to 5.51 in 2009. It subsequently increased to 7.77 in 2010 followed by a decrease to 3.80 in 2011 (Table 1).

The data quality allowed for specifying the significance of trend for these parameters from 2009 to 2011 only; other time periods were statistically excluded for lack of more than $10 \%$ of the data. From 2009 to 2011, the MRSA-admission incidence remained stable $(p=0.5796)$ whereas the nosocomial MRSA-incidence density $(p=0.0084)$ as well as the MRSA-days-associated nosocomial MRSA rate $(p=0.0437)$ decreased significantly.

There was a moderate positive correlation between the mean daily MRSA-burden and the screening rate (Spearman rank correlation coefficient $\mathrm{r}=0.32710$; p 0.0001 ) (Figure 2). Furthermore, there was a low negative correlation between the MRSA-days-associated nosocomial MRSA rate and the screening rate (Spearman rank correlation coefficient $r=-0.23829$; $p=0.0017$ ) (Figure 3). In Figures 2 and 3, the median and the IQR are plotted. In this way, hospitals beyond the
$50 \%$ range may be graphically detected, stimulating inspection and, if necessary, intervention measures.

\section{Discussion}

According to the antimicrobial resistance surveillance in Europe in 2010, MRSA is the most important cause of antibiotic resistant healthcare-associated infections worldwide. In 11 of 28 European countries, the percentage MRSA-isolates per $S$. aureus-isolates in blood cultures is higher than in Germany. The $S$. aureus resistance to meticillin in Germany in 2010 is still reported as increasing [4].

Due to an active search and destroy policy in Dutch hospitals, the incidence of hospital-associated cases and the rate of nosocomial transmission have been kept at a low level since decades [23]. Within the framework of two Dutch-German preventive network projects (EUREGIO MRSA-net and EurSafety Healthnet), we aimed to establish an adapted 'search and follow' strategy in hospitals in the German part of the Dutch-German border area [24]. This includes active search by region-wide screening for MRSA carriage at admission following the standardised implementation

\section{TABLE 1}

Admission screening rates and meticillin-resistant Staphylococcus aureus related rates in 40 hospitals in the EUREGIO, 2007-2011

\begin{tabular}{|c|c|c|c|c|c|}
\hline \multirow{2}{*}{ Parameter } & 2007 & 2008 & 2009 & 2010 & 2011 \\
\hline & Median (IQR) & Median (IQR) & Median (IQR) & Median (IQR) & Median (IQR) \\
\hline $\begin{array}{l}\text { Screening rate } \\
\text { (MRSA/100 patients admitted) }\end{array}$ & $\begin{array}{c}4.38 \\
(2.15-11.8)\end{array}$ & $\begin{array}{c}17.5 \\
(8.19-30.9)\end{array}$ & $\begin{array}{c}25.6 \\
(12.5-43.9)\end{array}$ & $\begin{array}{c}30.0 \\
(20.6-40.9)\end{array}$ & $\begin{array}{c}34 \cdot 4 \\
(27.4-51.6)\end{array}$ \\
\hline $\begin{array}{l}\text { MRSA admission incidence } \\
\text { (MRSA cases/100 patients admitted) }\end{array}$ & $\begin{array}{c}0.51 \\
(0.39-0.79)\end{array}$ & $\begin{array}{c}0.94 \\
(0.60-1.24)\end{array}$ & $\begin{array}{c}0.86 \\
(0.60-1.34)\end{array}$ & $\begin{array}{c}1.12 \\
\left(0.75^{-1.39)}\right.\end{array}$ & $\begin{array}{c}1.09 \\
(0.70-1.35)\end{array}$ \\
\hline $\begin{array}{l}\text { MRSA incidence density } \\
\text { (MRSA cases } / 1,000 \text { patient days) }\end{array}$ & $\begin{array}{c}0.87 \\
(0.56-1.21)\end{array}$ & $\begin{array}{c}1.37 \\
\left(0.93^{-1.89)}\right.\end{array}$ & $\begin{array}{c}1.62 \\
(1.01-2.20)\end{array}$ & $\begin{array}{c}1.63 \\
(1.19-2.35)\end{array}$ & $\begin{array}{c}1.54 \\
(0.92-2.27)\end{array}$ \\
\hline $\begin{array}{l}\text { Nosocomial MRSA incidence density } \\
\text { (nosocomial MRSA cases/1,000 patient days) }\end{array}$ & $\begin{array}{c}0.14 \\
(0.06-0.24)\end{array}$ & $\begin{array}{c}0.15 \\
(0.10-0.21)\end{array}$ & $\begin{array}{c}0.13 \\
(0.04-0.25)\end{array}$ & $\begin{array}{c}0.13 \\
(0.06-0.23)\end{array}$ & $\begin{array}{c}0.08 \\
(0.03-0.15)\end{array}$ \\
\hline $\begin{array}{l}\text { Mean daily MRSA burden } \\
\text { (MRSA-in-hospital days/10o patient days) }\end{array}$ & $\begin{array}{c}1.30 \\
(0.86-1.95)\end{array}$ & $\begin{array}{c}1.98 \\
(1.53-2.67)\end{array}$ & $\begin{array}{c}2.01 \\
(1.39-2.62)\end{array}$ & $\begin{array}{c}1.80 \\
(1.58-3.24)\end{array}$ & $\begin{array}{c}1.82 \\
(1.27-2.96)\end{array}$ \\
\hline $\begin{array}{l}\text { MRSA-days-associated nosocomial MRSA rate } \\
\text { (nosocomial MRSA-cases/1,00o MRSA days) }\end{array}$ & $\begin{array}{c}9.52 \\
(2.97-17.4)\end{array}$ & $\begin{array}{c}8.14 \\
(4.53-11.7)\end{array}$ & $\begin{array}{c}5 \cdot 51 \\
(3 \cdot 31-12.5)\end{array}$ & $\begin{array}{c}7.77 \\
(3.62-10.7)\end{array}$ & $\begin{array}{c}3.80 \\
(2.04-7.97)\end{array}$ \\
\hline
\end{tabular}

IQR: interquartile range; MRSA: meticillin-resistant Staphylococcus aureus.

TABLE 2

Numbers of meticillin-resistant Staphylococcus aureus cases documented in 40 German hospitals in the EUREGIO, 2007-2011

\begin{tabular}{|c|c|c|c|c|c|}
\hline \multirow{2}{*}{ Numbers of MRSA cases } & 2007 & 2008 & 2009 & 2010 & 2011 \\
\hline & n (\%) & n (\%) & n (\%) & n (\%) & n (\%) \\
\hline MRSA (total) & $2,351(100)$ & $3,522(100)$ & $4,206(100)$ & $4,276(100)$ & $4,512(100)$ \\
\hline MRSA (stratified)a & $1,864(100)$ & $3,263(100)$ & $3,759(100)$ & $4,150(100)$ & $4,347(100)$ \\
\hline Imported MRSA cases & $1,481(79)$ & $2,807(86)$ & $3,262(87)$ & $3,641(88)$ & $3,992(92)$ \\
\hline Nosocomial MRSA cases & $383(21)$ & $456(14)$ & $497(13)$ & $509(12)$ & $355(8)$ \\
\hline
\end{tabular}

MRSA: meticillin-resistant Staphylococcus aureus.

${ }^{a}$ Number of MRSA cases with available information allowing stratification as imported or nosocomial. 
of transmission-based precautions (hand hygiene, isolation and contact precaution) and decolonisation of MRSA carrier.

Here we present surveillance data obtained from this regional network aiming to prevent inter-institutional MRSA spread. We demonstrate that the network structures enabled the implementation of a risk-based admission screening approach. This was documented by a significant increase of nasopharyngeal MRSA screenings performed in the network hospitals after agreement upon a minimum standard for a screening regime. The aim of the network was to establish a screening of patients at a higher risk of MRSA carriage as defined by national German recommendations $[17,18]$. In 2011, the regional hospitals achieved a median screening rate of about $30 \%$, which argues for successful implementation of the screening-policy. The latter is supported by the study in which the same hospitals have assessed risk factors for MRSA carriage among all patients admitted during a one-month period in 2006 . A total of $35.6 \%$ of the patients exhibited at least one risk factor at admission. The observed admission MRSA prevalence was 1.6/100 patients [9].

The effect of the improved admission screening was demonstrated by an overall $92 \%$ increase of MRSA cases detected in the participating hospitals. Moreover, the MRSA admission-incidence nearly doubled (0.51 MRSA/100 patients in 2007 VS 1.09 MRSA/100 patients in 2011). This increase was not surprising as it is known that 69 to $85 \%$ of all MRSA cases are not detected if microbiological cultures are only performed for clinical reasons and screening is not implemented [25].

We assume that the risk-based screening strategy implemented in the participating hospitals still does not detect all MRSA cases, but, according to our data at least $68 \%$, due to the observed admission-incidence after full implementation (1.09/100 patients) which is

\section{FIGURE 2}

Moderate positive correlation between the mean daily meticillin-resistant Staphylococcus aureus burden and the screening rate, stratified by screening extent, of 40 German regional hospitals, EUREGIO, 2007-2011

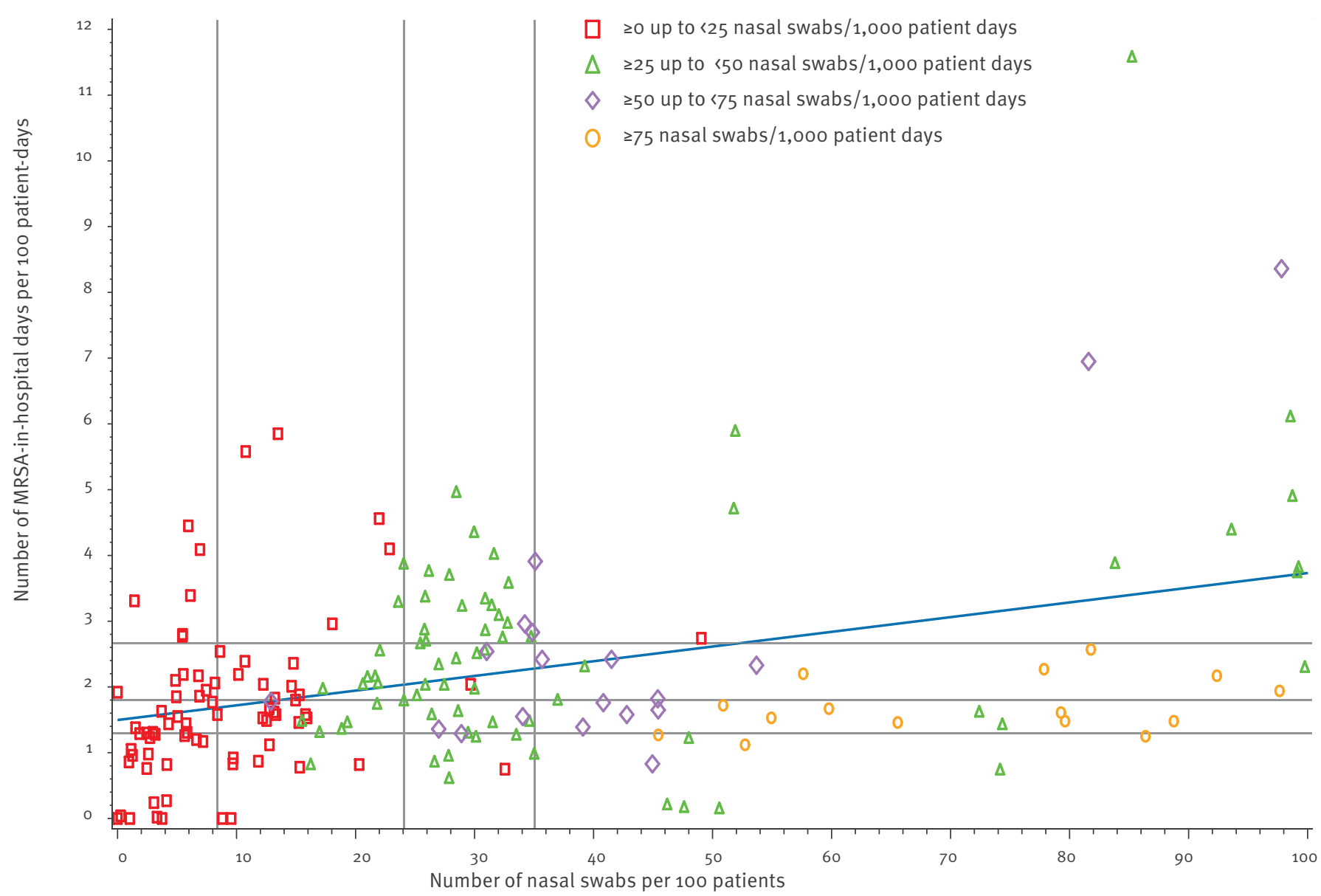


lower than the admission burden found when screening all regional patients at admission (1.6 MRSA cases/100 patients) [9].

Furthermore in 2011, the MRSA admission incidence was higher compared to the median incidence of 0.83 MRSA/100 patients described in 302 of 2,041 German hospitals participating in a German nationwide surveillance programme $[22,26]$. Since data from admission prevalence screening studies do not indicate that MRSA was more endemic in the EUREGIO compared to other parts of Germany [27], this difference is most likely due to the fact that the median screening rate was $34.4 / 100$ patients in the EUREGIO-hospitals, but much lower (9.39/100 patients) in hospitals taking part in the national surveillance programme. However, from 2009 to 2011, we observed a stabilisation of the MRSAincidence and the mean daily MRSA burden, which indicates a saturation of excess MRSA detection due to enhanced screening.
The improved detection of MRSA at admission also led to a decrease in the proportion of nosocomial MRSAcases within all MRSA cases. This is similar to results reported by other authors for 26 hospitals involved in the German nationwide MRSA surveillance from 2004 to 2006 [28], but has so far not been shown in a region-wide surveillance. From 2004 to 2009, the 111 hospitals, taking continuously part in the German national MRSA surveillance, reported a stable nosocomial MRSA incidence density of about 0.25 nosocomial MRSA cases per 1,000 patient days. A decrease was only observed in intensive care units [29]. The EUREGIO hospitals reported from 2007 to 2009 about 0.14 nosocomial MRSA cases per 1,000 patient days and even a significant reduction from 2009 to 2011.

The time-delayed reduction of nosocomial MRSA incidence density may be because the improved screening leads stepwise to better detection of MRSA cases in general, increasingly allowing better containment

\section{FIGURE 3}

Low negative correlation between the meticillin-resistant Staphylococcus aureus (MRSA)-days-associated nosocomial MRSArate and the screening rate, stratified by screening extent, of 40 German regional hospitals, EUREGIO, 2008-2011

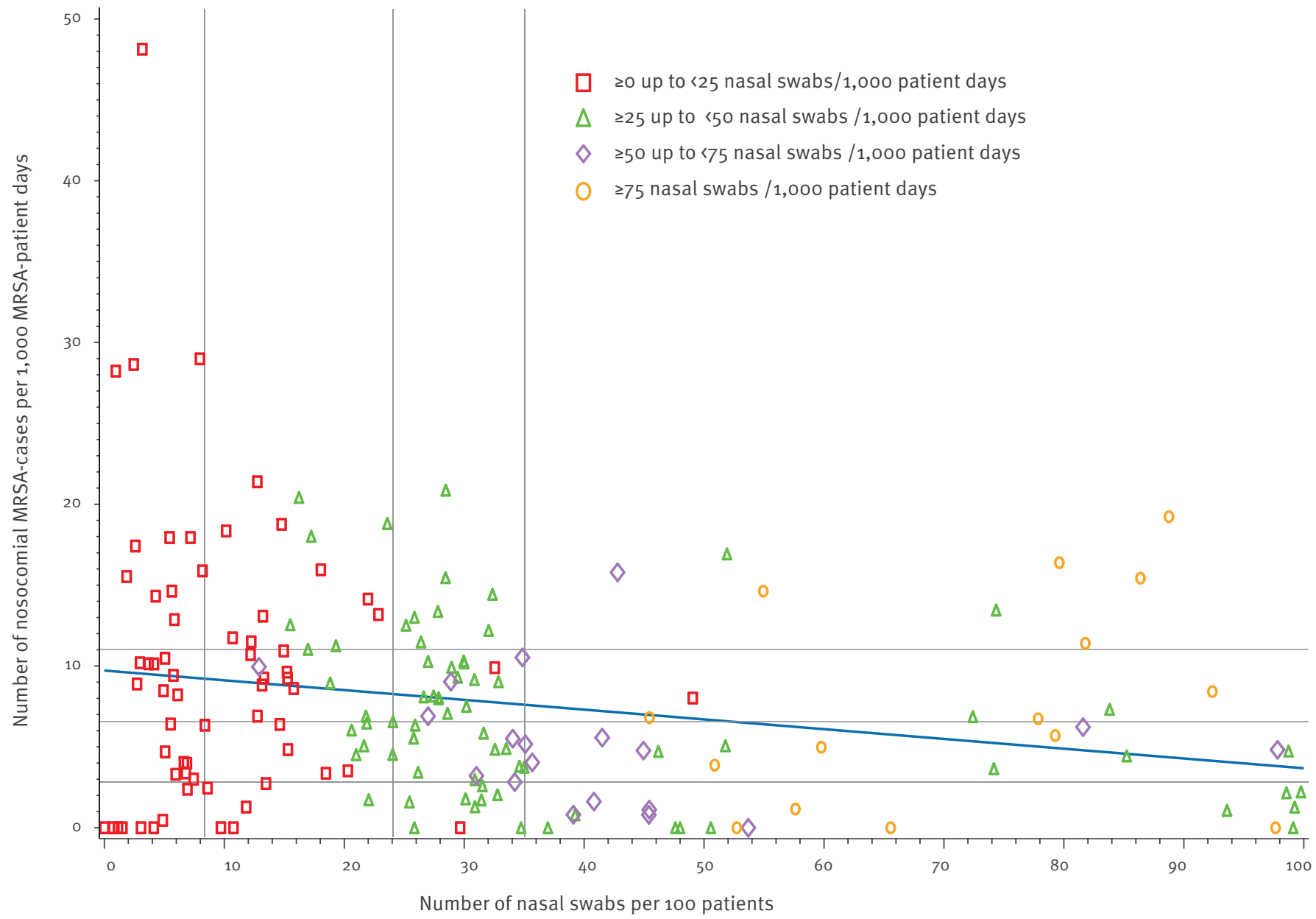

Low negative correlation between the MRSA-days-associated nosocomial MRSA-rate (number of nosocomial MRSA-cases/1,0oo MRSA-patientdays) and screening rate (admission screenings/100 patients). Each sign represents a network hospital once a year from 2007 to 2011 , with colour and shape reflecting the degree of screening implementation in nasal swabs per 1,000 patient days. The grey lines represent the respective median and interquartile ranges (IQR) of the nosocomial MRSA-cases per 1,000 MRSA days and nasal swabs per 100 patients. 
of the bacteria and more limiting spread in the hospital by MRSA-management measures like for example hand hygiene, contact precautions, and decolonisation efforts. The introduction of screening at admission and the increased awareness for MRSA in the hospitals might have led to more detection of nosocomial MRSAcases as well as to fewer MRSA cases not classifiable as imported or nosocomial ( $21 \%$ in 2007 vs $4 \%$ in 2011). On the other hand, there might be less 'false' nosocomial MRSA-cases (imported MRSA-cases detected via an isolate sampled from an inpatient after three days of hospital stay). Additionally, it may be that the hospitals improved the quality of the submitted data at least from 2009 to 2011, after two years of participation in the surveillance system. Furthermore the nosocomial MRSA incidence density was low (about 0.14 MRSA cases/1,000 patient days) in the 40 EUREGIOhospitals compared to 111 hospitals, which took part in the German national surveillance system (0.25 MRSA cases/1,000 patient days, stable from 2004 to 2009). The low number MRSA cases per 1,000 patient days in our hospitals reduced the probability for a (significant) decrease, which we could nevertheless demonstrate from 2009 to 2011.

For infection control staff, the advantage of improved MRSA detection at admission is that detection of nosocomial cases more reliably reflects cases of MRSA infection or colonisation which are caused by intrainstitutional transmission of the pathogen. This is important because a high number of nosocomial MRSA cases per 1,000 patient days (i.e. a nosocomial MRSAincidence in the range of the upper quartile of all hospitals taking part in a surveillance system) might be an indicator for deficits in infection control and/or for selection pressure due to use of antibiotics, which should be checked for possible improvements [30]. Locally, the knowledge of nosocomial MRSA cases enables more targeted reactions with respect to elucidating the transmission pathways and implementing measures appropriate to forestall further transmission.

Admission screening for MRSA carriage has been shown to be (cost-) effective in reducing both nosocomial infections and MRSA transmission on the wards, because it enables timely implementation of transmission-based precautions, isolation and decolonisation therapies [31,32]. Although, we did not assess to what extent isolation measures or decolonisation therapies were performed for the MRSA patients detected, applying a standardised panel of MRSA infection control measures in all participating hospitals was part of the network's quality goals and the implementation of these measures was controlled exemplarily by the regional public health authorities. Since nosocomial transmission is more probable in a hospital with a high mean daily MRSA burden than in a hospital with a low mean daily MRSA burden, the MRSA-days-associated nosocomial MRSA rate is used to compare hospitals as this rate takes into account the institutional mean daily MRSA-burden and thereby reflects the degree of transmission on the ward more reliably [33]. In this study, we observed a negative correlation between the slightly decreasing MRSA-days-associated nosocomial MRSA rate and the increasing screening rate. This also suggests that in those hospitals where screening was performed consistently it was followed by adequate hand hygiene, contact precautions, isolation of MRSAcarriers and subsequently led to a reduction of nosocomial transmissions.

Another important question related to the implementation of preventive strategies is whether they are effective in reducing the number of nosocomial MRSA cases. Many authors have investigated this issue with divergent results [31,34-36]. In this context, we found that from 2009 to 2011 the nosocomial incidence density decreased significantly from $0.13 / 1,000$ patient days to $0.08 / 1,000$ patient days. This indicates that after an implementation period, when MRSA carriers were detected at an early stage, the rate of nosocomial cross-transmission was reduced.

Besides screening, hand hygiene, isolation of MRSAcarriers and contact precautions the "search and follow'-strategy in the EUREGIO implies a post-discharge MRSA-case management outside the hospital [15]. In this way after a reduction of the nosocomial burden, the overall burden of MRSA-carriage in the region may be reduced.

This study also has some limitations. Analysis of MRSAsurveillance data of all hospitals in a regional network cannot adjust for all existing differences between the hospitals including different specialities, difference in the presence of infection control staff, different patient populations and case-mixes. Especially in 2007 and 2008, there were missing data concerning MRSA days or classification of MRSA cases as imported or nosocomial. We addressed the latter by not calculating statistical differences in the absolute numbers of nosocomial cases, in the MRSA-admission incidence, in the nosocomial MRSA incidence density and in the MRSA-days-associated nosocomial MRSA rate assessed between 2007 and 2008. However, during the course of the study, the quality of data collection was enhanced and the statistical tests indicated robust performance. Furthermore, we cannot adjust for differences in further hygiene measures implemented in the participating hospitals (e.g. different participation in the German version of the World Health Organization (WHO) campaign 'Clean Care is Safer Care' [37]). In the future, the network will have to focus on a structured assessment of nosocomial MRSA infections rather than cases of colonisation and infection to monitor the clinical impact of MRSA.

In conclusion, we documented the successful implementation of a screening programme in hospitals participating in a regional prevention network. This approach led to a significant increase of MRSA cases, but, eventually to a significant reduction of nosocomial 
MRSA-cases per 1,000 patient days. The data reflects a paradoxical situation ('MRSA-screening-paradox'): Initially, more MRSA carriers are found when more patients are screened. This may make some hospitals reluctant in establishing such a screening policy due to increasing and costly efforts to isolate patients in single rooms. However, only after few years, the nosocomial MRSA burden starts to reduce, which finally may encourage the hospitals to accept this burden of prevention. Since efforts of single hospitals may not change the MRSA-situation in the long run, this argues for establishing regional networks of healthcare providers sharing a common patient catchment population and synchronising prevention methods in the networks. Within such a network, surveillance data can be used for internal benchmarking as well as for validation and improvement of local standards. Thereby the network can support the work of local infection control personnel.

\section{Acknowledgements}

The EUREGIO MRSA-net and accordingly the EurSafety Health-Net project are financially supported by external funding within the community initiative Interreg IIIA/IVA programme 'Germany-Nederland' of the European Union and by the German states of North Rhine-Westphalia and Lower Saxony and the Dutch provinces Overijssel, Gelderland and Limburg (Reference no. of EUREGIO MRSA-net Twente/ Münsterland: 2-EUR-V-1=96; EurSafety Health-net: (Interreg IVa III-1-01=073). We acknowledge all the active participants of the EUREGIO MRSA-Net/ EurSafety Health-Net projects: The infection control nurses and the physicians responsible for infection control of the 40 participating hospitals, the participating microbiological laboratories Labor Nordwest in Schüttdorf and Labor Münster in Münster, Enzenauer Laboratory in Osnabrück, the project representatives appointed by the public health offices in the EUREGIO, especially Ms. Scherwinski and Ms. Winkler (both Borken), Dr. Toepper (Coesfeld), Dr. Bierbaum (Münster), Dr. Schmeer (Steinfurt), Dr. Zaps-Van Aken and Mr. Ziech (Warendorf). We would also like to thank Prof. Peters (Institute for Medical Microbiology, Münster) and Prof. Karch (Institute of Hygiene, Münster), Prof. Harmsen (University of Münster), Dr. Lehmann (NRW Institute of Health and Work), Ms. Schmidt and Ms. Lunemann (NRW Centre for Health) as well as the staff of the regional laboratories participating in the project. Moreover, we thank Prof. Mielke and Prof. Witte (both Robert Koch-Institute), the Euregional Centre for Health, the Euregio Gronau/Enschede and all other direct and indirect participants for supporting the project activities and their scientific advice.

\section{References}

1. Köck R, Becker K, Cookson B, van Gemert-Pijnen JE, Harbarth S, Kluytmans I, et al. Methicillin-resistant Staphylococcus aureus (MRSA): burden of disease and control challenges in Europe. Euro Surveill. 2010;15(41):pii=19688. Available from: http://www.eurosurveillance.org/ViewArticle. aspx?Articleld=19688. PMid:20961515.

2. de Kraker ME, Davey PG, Grundmann H. Mortality and hospital stay associated with resistant Staphylococcus aureus and Escherichia coli bacteremia: estimating the burden of antibiotic resistance in Europe. PLoS Med. 2011;8(10):e1001104. http:// dx.doi.org/10.1371/journal.pmed.1001104. PMid:22022233. PMCid:PMC3191157.

3. European Centre for Disease Prevention and Control/European Medicines Agency (ECDC/EMEA). Joint technical report. The bacterial challenge: time to react. Stockholm: ECDC/
EMEA; Sep 2009. Available from: http://www.ecdc.europa. eu/en/publications/Publications/0909 TER The Bacterial Challenge_Time_to_React.pdf.

4. European Centre for Disease Prevention and Control (ECDC). Antimicrobial resistance surveillance in Europe 2010. Annual Report on the European Antimicrobial Resistance Surveillance Network (EARS-Net). Stockholm: ECDC; 2011. Available from: http://www.ecdc.europa.eu/en/publications/ Publications/1111 SUR AMR data.pdf.pdf

5. van Cleef BA, Kluytmans JA, van Benthem BH, Haenen A, Monen J, Daniels-Haardt I, et al. Cross Border Comparison of MRSA Bacteraemia between The Netherlands and North Rhine-Westphalia (Germany): A Cross-Sectional Study. PLoS One. 2012;7(8):e42787. http://dx.doi.org/10.1371/journal. pone.0042787. PMid:22880109. PMCid:PMC3411841.

6. NRW Institute of Health and Work (LZG.NRW). Infektionsjahresbericht 2010. [Yearly infection report 2010]. Bielefeld: LZG.NWR. [Accessed 14 Sep 2012]. German. Available from: http://www.lzg.gc.nrw.de/themen/gesundheit_berichte daten/infektionsberichte/jahresbericht2010/index.html

7. Grundmann H, Aanensen DM, van den Wijngaard CC, Spratt BG, Harmsen D, Friedrich AW et al. Geographic distribution of Staphylococcus aureus causing invasive infections in Europe: a molecular-epidemiological analysis. PLoS Med. 2010;7(1):e1000215. http://dx.doi.org/10.1371/journal. pmed.1000215. PMid:20084094. PMCid:PMC 2796391.

8. Schaumburg F, Köck R, Mellmann A, Richter L, Hasenberg F, Kriegeskorte A, et al. Population Dynamics among MethicillinResistant Staphylococcus aureus Isolates in Germany during a 6-Year Period. J Clin Microbiol. 2012;50(10):3186-92. http://dx.doi.org/10.1128/JCM.01174-12. PMid:22814464. PMCid:PMC3457438.

9. Köck R, Brakensiek L, Mellmann A, Kipp F, Henderikx M, Harmsen D, et al. Cross-border comparison of the admission prevalence and clonal structure of methicillin-resistant Staphylococcus aureus. J Hosp Infect. 2009;71(4):320-6. http://dx.doi.org/10.1016/j.jhin.2008.12.001. PMid:19201056.

10. Robotham JV, Scarff CA, Jenkins DR, Medley GF. Meticillinresistant Staphylococcus aureus (MRSA) in hospitals and the community: model predictions based on the UK situation. J Hosp Infect. 2007;65 Suppl 2:93-9. http://dx.doi.org/10.1016/ S0195-6701(07)60023-1

11. Mattner F, Biertz F, Ziesing S, Gastmeier P, Chaberny IF. Longterm persistence of MRSA in re-admitted patients. Infection. 2010;38(5):363-71. http://dx.doi.org/10.1007/s15010-0100038-8. PMid:20602144. PMCid:PMC2945710.

12. Barnes SL, Harris AD, Golden BL, Wasil EA, Furuno JP. Contribution of interfacility patient movement to overall methicillin-resistant Staphylococcus aureus prevalence levels. Infect Control Hosp Epidemiol. 2011;32(11):10738. http://dx.doi.org/10.1086/662375. PMid:22011533. PMCid:PMC3331707.

13. Lee BY, McGlone SM, Wong KF, Yilmaz SL, Avery TR, Song $Y$, et al. Modeling the Spread of Methicillin-Resistant Staphylococcus aureus (MRSA) Outbreaks throughout the Hospitals in Orange County, California. Infect Control Hosp Epidemiol. 2011;32(6):562-72. http://dx.doi. org/10.1086/660014. PMid:21558768. PMCid:PMC3388111.

14. Ciccolini M, Donker T, Köck R, Mielke $M$, Hendrix R, Jurke $A$, et al. Infection prevention in a connected world: The case for a regional approach. Int J Med Microbiol. 2013;303(6-7):380-7 http://dx.doi.org/10.1016/j.ijmm.2013.02.003. PMid:23499307.

15. Friedrich AW, Daniels-Haardt I, Köck R, Verhoeven F, Mellmann A, Harmsen D, et al. EUREGIO MRSA-net Twente/Münsterland-a Dutch-German cross-border network for the prevention and control of infections caused by methicillin-resistant Staphylococcus aureus. Euro Surveill. 2008;13(35):pii=18965. Available from: http://www.eurosurveillance.org/ViewArticle. aspx?Articleld $=18965$

16. Donker T, Wallinga J, Slack R, Grundmann H. Hospital networks and the dispersal of hospital-acquired pathogens by patient transfer. PLoS One. 2012;7(4):e35002. http:// dx.doi.org/10.1371/journal.pone.0035002. PMid:22558106. PMCid:PMC3338821.

17. Commission for Hospital Hygiene and Infection Prevention at the Robert Koch-Institut. Recommendations for the prevention and control of methicillin-resistant Staphylococcus aureus isolates (MRSA) in hospitals and other healthcare facilities. GMS Krankenhhyg Interdiszip. 2009;4(1):Doco1. PMid:20204101. PMCid:PMC 2831515.

18. Commission for Hospital Hygiene and Infection Prevention at the Robert Koch-Institut. Kommentar zu den Empfehlungen zur Prävention und Kontrolle von MRSA-Stämmen in Krankenhäusern und anderen medizinischen Einrichtungen. [Comment on Recommendations for the prevention and control of methicillin-resistant Staphylococcus aureus isolates (MRSA) 
in hospitals and other healthcare facilities]. Epidemiologisches Bulletin. 2008;42:363-4. German.

19. Korczak D, Schöffmann C. Medical and health economic evaluation of prevention- and control measures related to MRSA infections or -colonisations at hospitals. GMS Health Technol Assess. 2010;6:Doc04. PMid:21289877. PMCid:PMC3010887.

20. Simon A, Exner M, Kramer A, Engelhart S. Implementing the MRSA recommendations made by the Commission for Hospital Hygiene and Infection Prevention (KRINKO) of 1999 current considerations by the DGKH Management Board. GMS Krankenhhyg Interdiszip. 2009;4(1):Doc02. PMid:20204102. PMCid:PMC 2831514.

21. Eurostat. Regulation (EC) No $1059 / 2003$ of the European Parliament and of the council of 26 May 2003 on the establishment of a common classification of territorial units for statistics (NUTS). [Accessed 02 Sep 2013]. Available from: http://eur-lex.europa.eu/LexUriServ/LexUriServ.do?uri=CONSL EG:2003R1059:20110207:EN:PDF

22. German National Reference Center for Surveillance of Nosocomial Infections (NRZ). [MRSA Reference data 2011 of MRSA hospital infection surveillance system (KISS)]. Berlin: NRZ. [Accessed 01 Sep 2012]. German. Available from: http://www.nrz-hygiene.de/fileadmin/nrz/module/mrsa/ MRSAReferenz2011_stand_20_07_2012.pdf

23. Vos MC, Behrendt MD, Melles DC, Mollema FP, de Groot W, Parlevliet G, et al. 5 years of experience implementing a methicillin-resistant Staphylococcus aureus search and destroy policy at the largest university medical center in the Netherlands. Infect Control Hosp Epidemiol. 2009;30(10):97784. http://dx.doi.org/10.1086/605921. PMid:19712031.

24. Friedrich AW. [EUREGIO MRSA-net Twente/Munsterland: "'search \& follow"' by Euregional network building]. Gesundheitswesen. 2009;71(11):766-70. German. http://dx.doi. org/10.1055/s-0029-1241892. PMid:19937565.

25. Salgado CD, Vos MC, Farr BM. Universal screening for methicillin-resistant Staphylococcus aureus by hospitals. JAMA. 2008;300(5):503-4. http://dx.doi.org/10.1001/ jama.300.5.503-b. PMid:18677019.

26. German Hospital Society (DKG). [Preliminary key data of hospital statistics 2011]. [Accessed 14 Sep 2012]. German. Available from: http://www.dkgev.de/media/file/12149. RS266-12_KH-Statistik-2011_vorlaeufig_A1.pdf

27. Köck R, Mellmann A, Schaumburg F, Friedrich AW, Kipp F, Becker K. The Epidemiology of Methicillin-Resistant Staphylococcus aureus (MRSA) in Germany. Dtsch Arztebl Int. 2011;108(45):761-7. PMid:22163252. PMCid:PMC3230165.

28. Chaberny IF, Sohr D, Rüden H, Gastmeier P. Surveillance of MRSA over 3 years shows a significant reduction of the nosocomial MRSA incidence density - analysis of 26 German MRSA-KISS hospitals. J Hosp Infect. 2006;64 Suppl 1:S82. http://dx.doi.org/10.1016/S0195-6701(06)60273-9

29. Gastmeier P, Schwab F, Chaberny I, Geffers C. Individual units rather than entire hospital as the basis for improvement: the example of two Methicillin resistant Staphylococcus aureus cohort studies. Antimicrob Resist Infect Control. 2012;1(1):8 http://dx.doi.org/10.1186/2047-2994-1-8. PMid:22958320. PMCid:PMC3436609.

30. Meyer E, Gastmeier P, Weizel-Kage D, Schwab F. Associations between nosocomial meticillin-resistant Staphylococcus aureus and nosocomial Clostridium difficile-associated diarrhoea in 89 German hospitals. J Hosp Infect. 2012;82(3):181-6. http://dx.doi.org/10.1016/j.jhin.2012.07.022. PMid:23021304.

31. Diller R, Sonntag AK, Mellmann A, Grevener K, Senninger $\mathrm{N}$, Kipp F, et al. Evidence for cost reduction based on preadmission MRSA screening in general surgery. Int J Hyg Environ Health. 2008;211(1-2):205-12. http://dx.doi.org/10.1016/j. ijheh.2007.06.001. PMid:17692566.

32. Wernitz MH, Keck S, Swidsinski S, Schulz S, Veit SK. Cost analysis of a hospital-wide selective screening programme for methicillin-resistant Staphylococcus aureus (MRSA) carriers in the context of diagnosis related groups (DRG) payment. Clin Microbiol Infect. 2005;11(6):466-71. http://dx.doi.org/10.1111/ j.1469-0691.2005.01153.x. PMid:15882196.

33. Gastmeier P, Chaberny IF. [Which rate describes the MRSA situation appropriately]? Dtsch med Wochenschr. 2007;132(27):1480-2. German. http://dx.doi. org/10.1055/s-2007-982056. PMid:17583833.

34. Camus C, Bellissant E, Legras A, Renault A, Gacouin A, Lavoué $S$, et al. Randomized comparison of 2 protocols to prevent acquisition of methicillin-resistant Staphylococcus aureus: results of a 2 -center study involving 500 patients. Infect Control Hosp Epidemiol. 2011;32(11):1064-72. http://dx.doi. org/10.1086/662180. PMid:22011532.
35. Harbarth S, Fankhauser C, Schrenzel J, Christenson J, Gervaz P, Bandiera-Clerc C, et al. Universal screening for methicillin-resistant Staphylococcus aureus at hospital admission and nosocomial infection in surgical patients. JAMA. 2008;299(10):1149-57. http://dx.doi.org/10.1001/ jama.299.10.1149. PMid:18334690.

36. Harbarth S, Masuet-Aumatell C, Schrenzel J, Francois P, Akakpo C, Renzi G, et al. Evaluation of rapid screening and pre-emptive contact isolation for detecting and controlling methicillin-resistant Staphylococcus aureus in critical care: an interventional cohort study. Crit Care. 2006;10(1):R25. http://dx.doi.org/10.1186/cc3982. PMid:16469125. PMCid:PMC1550853.

37. World Health Organization (WHO). Clean Care is Safer Care. Geneva: WHO. [Accessed 21 Aug 2013]. Available from: http:// www.who.int/gpsc/en/ 